\title{
Scutellaria barbata D. Don inhibits 5-fluorouracil resistance in colorectal cancer by regulating PI3K/AKT pathway
}

\author{
JIUMAO LIN ${ }^{1,2^{*}}$, JIANYU FENG ${ }^{1,2^{*}}$, HONG YANG $^{1}$, ZHAOKUN YAN $^{1}$, QIONGYU LI $^{1}$, \\ LIHUI WEI $^{1,2}$, ZIJUN LAI ${ }^{1}$, YIYI JIN ${ }^{1}$ and JUN PENG ${ }^{1,2}$ \\ ${ }^{1}$ Academy of Integrative Medicine Biomedical Research Center, ${ }^{2}$ Fujian Key Laboratory of Integrative Medicine on Geriatrics, \\ Fujian University of Traditional Chinese Medicine, Fuzhou, Fujian 350122, P.R. China
}

Received March 6, 2017; Accepted July 31, 2017

DOI: $10.3892 /$ or.2017.5892

\begin{abstract}
Fluorouracil (5-FU) resistance or multidrug resistance (MDR) has become a major obstacle in clinical treatment of cancers including colorectal cancer (CRC). Aberrant activation of phosphatidylinositol 3 kinase (PI3K)/ protein kinase B (AKT) pathway may lead to unlimited growth and chemoresistance in CRC cells, which thus could be a promising therapeutic target. As a long-term used traditional Chinese folk-medicine, Scutellaria barbata D. Don (SB) processes specific anticancer activity, but its activity against cancer chemoresistance is less known. Therefore, using a 5-FU-resistant CRC cell line HCT-8/5-FU, in this study we evaluated the therapeutic efficacy of the ethanol extracts of SB (EESB) against 5-FU resistance and explored the possible molecular mechanisms. We found that EESB significantly suppressed proliferation and promoted apoptosis in HCT-8/5-FU cells. Additionally, EESB displayed remarkable effect enhancing the retention of the ATP-binding cassette (ABC) transporter substrate, rhodamine-123 (Rh-123) in HCT-8/5-FU cells. Furthermore, EESB obviously downregulated the expression of cyclin D1, Bcl-2 and ABCG2, while upregulated p21 and Bax expression. Moreover, EESB showed a prominent suppressive effect on the activation of PI3K/AKT pathway. The findings suggested that Scutellaria
\end{abstract}

Correspondence to: Dr Jun Peng, Academy of Integrative Medicine Biomedical Research Center, Fujian University of Traditional Chinese Medicine, 1 Qiuyang Road, Minhou Shangjie, Fuzhou, Fujian 350122, P.R. China

E-mail: pjunlab@hotmail.com

*Contributed equally

Abbreviations: EESB, ethanol extract of Scutellaria Barbata D. Don; CRC, colorectal cancer; MDR, multidrug resistance; 5-FU, 5-fluorouracil; ABC transporter, ATP-binding cassette transporter; DAPI, 2-(4-Amidinophenyl)-6-indolecarbamidine dihydrochloride; Rh-123, rhodamine-123

Key words: Scutellaria barbata D. Don, colorectal cancer, 5-fluorouracil, drug resistance, PI3K/AKT pathway barbata D. Don was able to inhibit chemoresistance in colorectal cancer by suppression of the PI3K/AKT pathway.

\section{Introduction}

Colorectal cancer (CRC) has become a serious concern for public health issues, with more than million new cases each year $(1,2)$. The CRC morbidity keeps climbing and its estimated figure may reach 2.4 million in 2035 globally $(3,4)$. Surgery assisted with chemotherapy represents the first-line strategy for most patients (5). Currently, the management of chemotherapy is applied using various chemoreagents including 5-fluorouracil (5-FU), leucovorin (LV), oxaliplatin, irinotecan, capecitabine, bevacizumab and cetuximab, either as single agent or in combination (6). However, chemoresistance greatly limits the clinical outcome of the treatment on CRC patients, resulting into most cancer-related deaths.

5-FU as the most commonly used agent in many chemotherapy regimens, may lead to acquired resistance in cancer cells. Moreover, 5-FU-resistant cells can develop resistance to other drugs, like those with very different acting mechanisms and/or chemical structures, which is defined as multidrug resistance (MDR) (7). The mechanisms of chemoresistance are complicated, including the increase in drug efflux, reduction in drug absorption, changes in the targets of anticancer drugs, decrease in drug activity, enhancement of DNA repair following damage, deregulation of signaling pathways (8). PI3K/AKT pathway exerts essential roles in survival, proliferation, migration and differentiation of cells. However, once it is aberrantly activated, it will underlie the biology of cancer and enhance drug efflux by highly expressing $\mathrm{ABC}$ transporters, reducing the response to 5-FU or other chemotherapeutic agents (9-11). Thus, the inhibition of PI3K/AKT pathway becomes a promising therapeutic target.

The existing chemical reversal agents targeting different mechanisms of MDR are of poor selectivity and with apparent side effects (12). Besides, the genomic instability and heterogeneity of cancer cells make it ineffective or even encounter drug resistance during the single-target treatment (13), which increases the urgency for developing new therapeutic approaches. Scutellaria barbata D. Don (SB) is a well-known traditional Chinese folk-medicine that has been widely used in the treatment of various kinds of 
cancers including CRC (14). As reported previously, the ethanol extract of SB (EESB) possesses significant antitumor activity by promoting cell apoptosis, as well as inhibiting cell proliferation and tumor angiogenesis via modulating several pathways (15-17). However, its activity against cancer chemoresistance is less known. Therefore, using a 5-FU-resistant CRC cell line HCT-8/5-FU, in this study we evaluated the therapeutic efficacy of the ethanol extracts of SB (EESB) against 5-FU resistance and explored the possible molecular mechanisms.

\section{Materials and methods}

Materials and reagents. Roswell Park Memorial Institute medium-1640 (RPMI-1640, C11875500BT), fetal bovine serum(FBS,\#10099-141),0.25\% trypsin-EDTA (\#25200-072), penicillin-streptomycin (SV30010), DreamTaq Green PCR Master Mix (K1081), Pierce RIPA buffer (\#89901), Pierce BCA Protein assay kit (\#23227) and SuperSignal ${ }^{\mathrm{TM}}$ West Pico Chemiluminescent Substrate (\#34080) were obtained from Thermo Fisher Scientific, Inc. (Waltham, MA, USA). Culture flask and plates were from NEST Biotechnology Co., Ltd. (Jiangsu, China). 5-FU (\#040302) were obtained from Xudong Haipu Pharmaceutical Co., Ltd. (Shanghai, China). 3-[4,5-dimethylthiazol-2-yl]-2,5-diphenyl-tetrazolium bromide (MTT, M8180) was from Solarbio Science and Technology (Beijing, China). Annexin V-FITC apoptosis detection kit (KGA108) was obtained from KeyGen Biotech Co., Ltd. (Jiangsu, China). DAPI staining solution (C1005) and Rho-123 (C2007) were obtained from Beyotime (Shanghai, China). RNAiso plus (\#9109) and PrimScript RT reagent kit with gDNA Eraser (RR047A) were from Takara Biotechnology Co., Ltd. (Dalian, China). The nitrocellulose (NC) membrane (0.45 $\mu \mathrm{m}$, HATF00010) was obtained from Millipore (Billerica, MA, USA). Rabbit monoclonal antibody against cyclin D1 (\#2978), p21 (\#2947S), PI3K (\#4257), p-AKT (\#4058) and AKT (\#4685) and rabbit polyclonal antibody against $\beta$-actin (\#4967) were obtained from Cell Signaling (Beverly, MA, USA). Rabbit polyclonal antibody against Bcl-2 (ab59348), Bax (ab53154), and ABCG2 (ab63907) were from Abcam (Cambridge, MA, USA). HRP-conjugated goat anti-rabbit secondary antibody (E030120) was from Earthox (Millbrae, CA, USA).

Preparations of EESB. EESB powder was prepared as previously described (15) and dissolved into DMSO to make a stock solution with a concentration of $500 \mathrm{mg} / \mathrm{ml}$, and stored at $-20^{\circ} \mathrm{C}$. Immediately before each experiment, stock solution was diluted into culture medium to make different working concentrations of EESB. The content of DMSO in the medium was $<0.5 \%$.

Cell culture. Human CRC cell lines HCT-8/5-FU and the parental HCT- 8 cells were obtained from KeyGen Biotech Co., Ltd. Cells were cultured in RPMI-1640 complete medium, containing $10 \%(\mathrm{v} / \mathrm{v})$ FBS and $1 \%$ antibiotics, and at condition of $37^{\circ} \mathrm{C}, 5 \% \mathrm{CO}_{2}$ in an incubator with saturated humidity (Forma 3110; Thermo Fisher Scientific, Inc. The HCT-8/5-FU cells were grown in the complete medium with $15 \mu \mathrm{g} / \mathrm{ml} 5-\mathrm{FU}$.
Cell viability analysis. Cell viability of HCT-8 and HCT-8/5-FU was estimated by MTT assay. In short, cells were

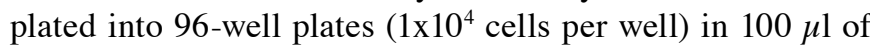
medium. After $12 \mathrm{~h}$, cells were dealt with different doses of 5-FU or EESB for indicated time. Equivoluminal DMSO was used as the vehicle control. Details for MTT assay were as described before (15). The resistance index (RI) was used to analyze the drug resistance of the HCT-8/5-FU cells to 5-FU. RI was calculated by dividing the dose of 5-FU required to inhibit growth by $50 \%\left(\mathrm{IC}_{50}\right)$ for HCT-8/5-FU cells by the $\mathrm{IC}_{50}$ value for the parental cells (HCT-8). IC $_{50}$ values were assessed using non-linear regression analysis.

Cellular morphology observation. HCT-8/5-FU cells were plated into 6-well plates at a density of $5 \times 10^{5}$ cells/well in $2 \mathrm{ml}$ complete medium and administered with $\operatorname{EESB}(0,0.5,1.0$ and $1.5 \mathrm{mg} / \mathrm{ml}$ ) for $24 \mathrm{~h}$. A phase-contrast microscope (Leica Camera AG; Leica Microsystems, Wetzlar, Germany) was used to observe cell morphology, and images were photographed at a magnification of $\times 200$.

Colony formation. HCT-8/5-FU cells were seeded into 6-well plates at a density of $5 \times 10^{5}$ cells/well in $2 \mathrm{ml}$ complete medium and intervented with $\operatorname{EESB}(0,0.5,1.0$ and $1.5 \mathrm{mg} / \mathrm{ml})$ for $24 \mathrm{~h}$. Subsequently, cells were collected, diluted with fresh medium without EESB, and reseeded into 6-well plates at a density of 1,000 cells/well in $2 \mathrm{ml}$. The medium was replaced with fresh medium every four days, and 10 days later, colonies were fixed with $4 \%$ paraformaldehyde, stained with $0.01 \%$ crystal violet and photographed.

Apoptosis detection with DAPI and Annexin V-FITC/PI staining. DAPI staining was used to determine apoptosis of HCT-8/5-FU cells after EESB treatment. Briefly, 4\% paraformaldehyde was added to fix the cells at room temperature for 15 min and washed with PBS 3 times. Subsequently, DAPI solution was added to stained cells at room temperature for $10 \mathrm{~min}$ and washed with PBS 3 times. DAPI stained cells were visualized using an inverted fluorescence microscope (DMI4000B; Leica Microsystems) with $100 \mathrm{~W}$ mercury lamp light source using UV filter cubes. Excitation was $340 \mathrm{~nm}$ (long pass). Furthermore, Annexin V-FITC/PI double staining followed by FACSCalibur determination were used to verify the apoptosis-inducing effect of EESB. Procedures were performed according to the manufacturer's instructions. Herein, Annexin V/PI double-negative population (in the lower left quarter of FACS diagram) indicates living cells; Annexin V-positive/PI-negative or Annexin V/PI doublepositive population (in the lower right quarter or upper right quarter of FACS diagram) stands for cells undergoing early or late apoptosis, respectively. Final results are represented by calculating the percentage of both early and late apoptosis as total apoptosis.

Rhodamine-123 (Rh-123) exclusion. Rh-123 is the substrate of the ATP-binding cassette (ABC) transporter, and the Rh-123 exclusion assay was used to investigate the reversal effect according to the retention of Rh-123 after treatment. Briefly, HCT-8/5-FU cells were treated with EESB $(0,0.5,1.0$ and $1.5 \mathrm{mg} / \mathrm{ml}$ ) for $24 \mathrm{~h}$ before collected, and a total of $10^{6}$ cells 
Table I. Primer sequences for RT-PCR.

\begin{tabular}{ll}
\hline Gene & \multicolumn{1}{c}{ Primers (5'-3') } \\
\hline Cyclin D1 & F: TGG ATG CTG GAG GTC TGC GAG GAA \\
& R: GGC TTC GAT CTG CTC CTG GCA GGC \\
p21 & F: GCG ACT GTG ATG CGC TAA TGG \\
& R: TAG AAA TCT GTC ATG CTG GTC TGC \\
Bcl-2 & F: CAG CTG CAC CTG ACG CCC TT \\
& R: AGT CAG TTC CTT GTG GAG CC \\
Bax & F: TGC TTC AGG GTT TCA TCC AGG \\
& R: TGG CAA AGT AGA AAA GGG CGA \\
ABCG2 & F: GCC GTG GAA CTC TTT GTG GTA G \\
& R: ACA GCA AGA TGC AAT GGT TGT \\
F-actin & F: CCA GGG CGT TAT GGT AGG CA \\
& R: TTC CAT ATC GTC CCA GTT GGT
\end{tabular}

in $1 \mathrm{ml}$ medium with $5 \mu \mathrm{g} / \mathrm{ml} \mathrm{Rh}-123$ were incubated at $37^{\circ} \mathrm{C}$ for $10 \mathrm{~min}$. Then cells were washed twice with pre-cold PBS and resuspended in $0.5 \mathrm{ml} \mathrm{PBS}$, followed by 30 -min incubation at $37^{\circ} \mathrm{C}$. Fluorescence intensity was detected at $488 \mathrm{~nm}$ to determine the intracellular content of Rh-123 and quantitated using the FACSCalibur flow cytometer (BD FACSCalibur; Becton-Dickinson, CA, USA). The results were indicated as the mean fluorescence intensity of $\mathrm{Rh}-123$.

Reverse transcription polymerase chain reaction (RT-PCR) analysis. HCT-8/5-FU cells $\left(4 \times 10^{5}\right)$ were plated into 6-well plates in $2 \mathrm{ml}$ complete medium and treated with $\operatorname{EESB}(0,0.5$, 1.0 and $1.5 \mathrm{mg} / \mathrm{ml}$ ) for $24 \mathrm{~h}$. Total RNA were extracted with RNAiso plus and reverse-transcribed by the PrimScript RT reagent kit with gDNA Eraser, according to the manufacturer's instructions. The cDNA was used to measure the mRNA amount of cyclin D1, p21, Bcl-2, Bax and ABCG2 by RT-PCR. $\beta$-actin was used as an internal control. The RT-PCR conditions were performed as follows: denaturation at $94^{\circ} \mathrm{C}$ for $40 \mathrm{sec}$, annealing at $60^{\circ} \mathrm{C}$ for $40 \mathrm{sec}$ and extension at $72^{\circ} \mathrm{C}$ for $45 \mathrm{sec}$ for 30 cycles. The sequences of primers are listed in Table I.

Western blot analysis. HCT-8/5-FU cells were treated as previously described, then Pierce RIPA buffer, which consist of several protein inhibitors, was used to lyse the cells. The lysates were then centrifuged for $20 \mathrm{~min}$ at the condition of $14,000 \mathrm{rpm}$ and low temperature, and the concentrations of supernatant were detected by BCA Protein Assay Reagent kit. Protein $(50 \mu \mathrm{g})$ for each sample was loaded onto sodium dodecyl sulfate polyacrylamide gel electrophoresis (SDS-PAGE) and resolved using $20 \mathrm{~V}$ for $10 \mathrm{~min}$, subsequently $80 \mathrm{~V}$ for $30 \mathrm{~min}$ followed by $120 \mathrm{~V}$ for $1 \mathrm{~h}$, then transferred onto nitrocellulose (NC) membranes. After blocking with 5\% non-fat dry milk, membranes were incubated with cyclin D1, p21, Bcl-2, Bax, ABCG2, PI3K, p-AKT, AKT or $\beta$-actin, respectively (1:1,000 dilution) overnight at $4^{\circ} \mathrm{C}$, and then incubated with HRP-conjugated anti-rabbit secondary antibodies (1:5,000 dilution) for $1 \mathrm{~h}$ at room temperature. The membranes were
A

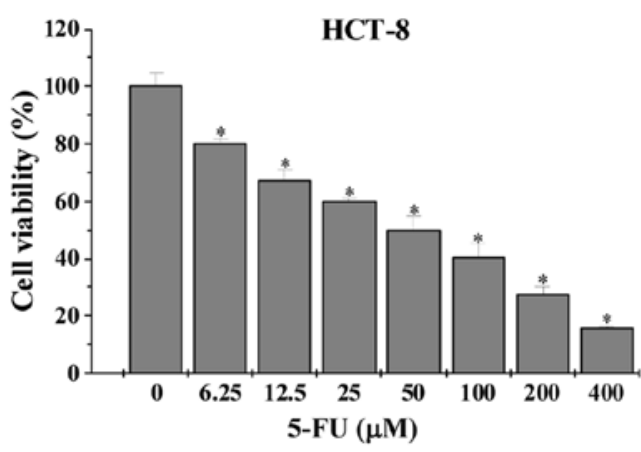

B

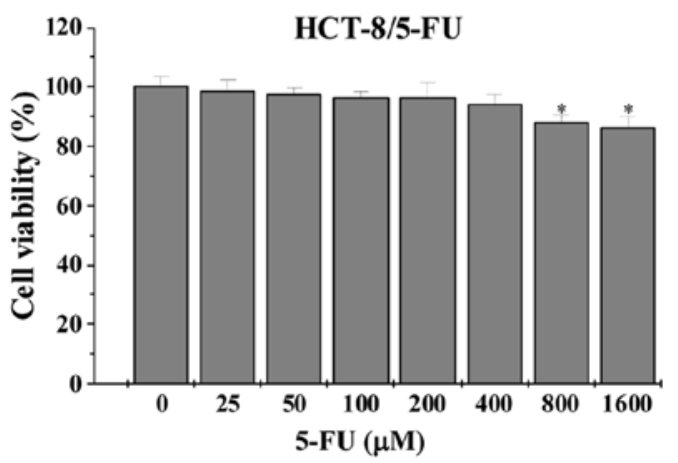

C $\quad 125_{1} \quad$ HCT-8/5-FU

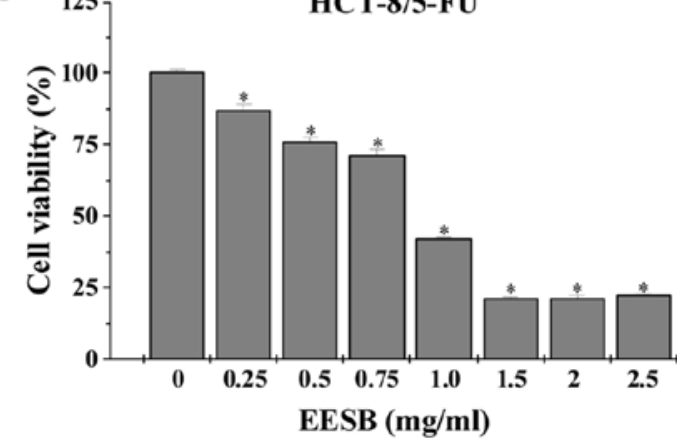

Figure 1. EESB inhibits 5-FU resistance in CRC HCT-8 cells. (A) HCT-8 and (B) HCT-8/5-FU were treated with 5-FU at different concentrations for $48 \mathrm{~h}$. (C) HCT-8/5-FU were treated with different concentrations of EESB for $24 \mathrm{~h}$. Cell viability was measured by MTT assay. Data were normalized to the viability of control cells (100\%) and were expressed as mean \pm SD of at least three independent experiments. ${ }^{*} \mathrm{P}<0.05$.

then exposed to enhanced chemiluminescence (ECL) detection using SuperSignal ${ }^{\mathrm{TM}}$ West Pico Chemiluminescent Substrate. Images were obtained with ChemiDoc $\mathrm{XRS}^{+}$imaging system (Bio-Rad Laboratories, Inc., Hercules, CA, USA). The images were analysed by Image Lab $^{\mathrm{TM}}$ Software (Version 3.0).

Statistical analysis. All data were collected based on the mean of three experiments. Statistical analysis was performed using SPSS software (version 17.0) for Windows (SPSS, Inc. Chicago, IL, USA) using one-way ANOVA. $\mathrm{P}<0.05$ was considered as statistically significant.

\section{Results}

EESB overcomes 5-FU resistance in CRC HCT-8 cells. After exposure to 5-FU or EESB, the viability of HCT-8 and HCT-8/5-FU cells was examined by MTT assay. Data in Fig. 1 
A
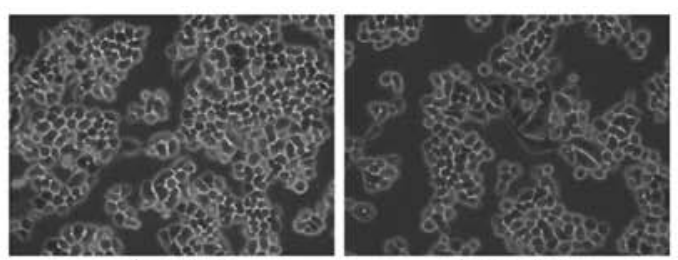

$0 \mathrm{mg} / \mathrm{ml}$

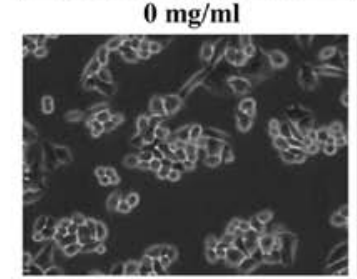

$1.0 \mathrm{mg} / \mathrm{ml}$

B

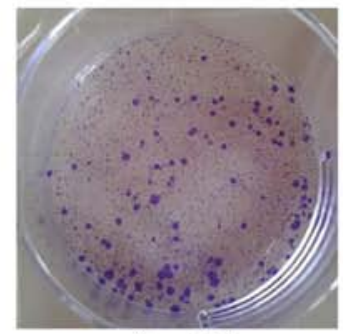

$0 \mathrm{mg} / \mathrm{ml}$

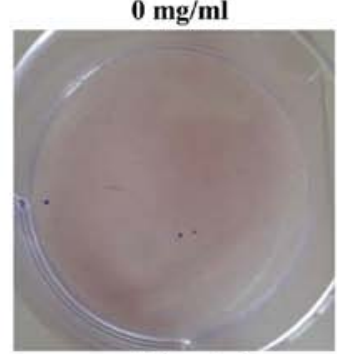

$1.0 \mathrm{mg} / \mathrm{ml}$

C

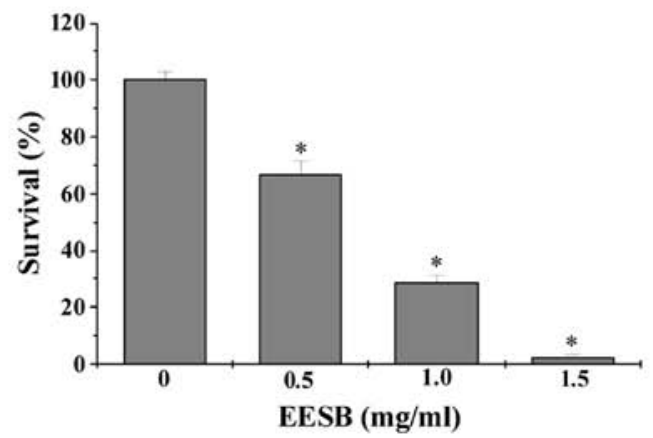

Figure 2. Effect of EESB on growth of HCT-8/5-FU cells. HCT-8/5-FU cells were treated with different concentrations of EESB for $24 \mathrm{~h}$. (A) Morphological changes were observed using a phase-contrast microscopy. Photographs were taken at a magnification of x200. Images are representative of three independent experiments. (B) Colonies were stained with crystal violet, $(C)$ and counted in each well. Data were normalized to the control cells $(100 \%)$ and were expressed as mean \pm SD of three independent experiments. ${ }^{*} \mathrm{P}<0.05$, versus control cells.

showed that the $\mathrm{IC}_{50}$ value in HCT- 8 and HCT-8/5-FU cells were 0.11 and $2.91 \mathrm{mM}$, respectively, leading to a resistance index (RI) of 25.34. However, treatment with $0.25-2.5 \mathrm{mg} / \mathrm{ml}$ of EESB dose-dependently reduced HCT-8/5-FU cell viability by $12.92-78.01 \%$, as compared with untreated cells.

EESB inhibits proliferation, promotes apoptosis and inhibits drug efflux in HCT-8/5-FU cells. Effect of EESB on cell

growth was determined by observation of cell morphology and colony formation. As shown in Fig. 2A, the monolayers of untreated HCT-8/5-FU cells were crowded and disorganized, while the cell density of treated ones showed a reduction in the confluent monolayers. In addition, the colonies reduced after EESB treatment in a dose-dependent manner (Fig. 2B and C). Cell apoptosis was assessed by DAPI and Annexin V/ PI staining, respectively. When apoptosis occurs, cells will experience a process of chromatin condensation, the nucleus shrinks and DNA fragments, so that they stain by DAPI with strong light. As shown in Fig. 3A and B, the percentage of cells with strong dye treated with $0,0.5,1$ and $1.5 \mathrm{mg} / \mathrm{ml}$ of EESB was $2.90,31.81,79.59$ and $94.31 \%$, respectively $(\mathrm{P}<0.05)$. Then, we used Annexin V/PI staining to verify this result. As shown in Fig. 3C and D, with the indicated concentration of EESB treatment, the percentage of total apoptotic cells increased from 3.2 to $33.9 \%$, in a dose-dependent manner. To find out the effects of EESB on drug efflux, the intracellular accumulation of Rh-123 was measured in EESB-treated HCT-8/5-FU cells. Data in Fig. 4 show that when compared with untreated controls, HCT-8/5-FU cells treated with EESB for $24 \mathrm{~h}$ had a distinct rise in Rh-123 intracellular level.

EESB regulates expression of cyclin D1, p21, Bcl-2, Bax and ABCG2 in HCT-8/5-FU cells. RT-PCR and western blot analyses were used to determine the mRNA and protein levels of cyclin D1, p21, Bcl-2, Bax and ABCG2 in EESB-treated HCT-8/5-FU cells. According to results (Fig. 5), pro-proliferative cyclin D1 and anti-apoptotic Bcl-2 were reduced in both mRNA and protein expression under EESB treatment while anti-proliferative $\mathrm{p} 21$ and pro-apoptotic Bax showed increased levels. Besides, the ABC transporter, ABCG2, was significantly downregulated by EESB treatment.

EESB suppresses the activation of PI3K/AKT pathway in HCT-8/5-FU cells. The activation of PI3K/AKT signaling was evaluated by western blot analysis. As shown in Fig. 6, EESB treatment remarkably decreased $\mathrm{PI} 3 \mathrm{~K}$ protein expression and AKT phosphorylation level, while the protein expression of total AKT was not affected.

\section{Discussion}

Currently, 5-FU-based regimens still are chosen for most CRC patients as a therapy. However, the sensitivity to different chemotherapeutics varies widely from individual to individual. Due to 5-FU resistance or MDR and the fact that normal cells cannot stand a certain level of toxicity, systemic chemotherapy using 5-FU-based regimens shows a poor response of 10-20\% (18-21). A few mechanisms have been proposed for the resistance to chemotherapeutic agents in CRC cells.

Among those proposals, the disorder in cell proliferation contributes to MDR. For example, cancer cells survive by controlling the cell cycle. Under this main working mechanism, cell cycle checkpoints may be activated when cancer cells are in drug-toxicity, so that cell cycle cannot progress. This leads to the enhancement of damage repair and resistance phenotype. Cyclin D1 and p21 are crucial regulators in the cell cycle. By regulating with these two regulators, the 
A

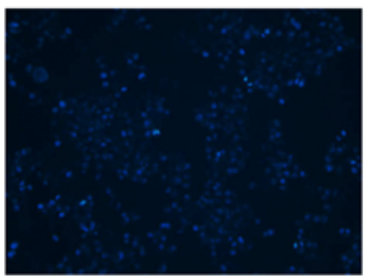

$0 \mathrm{mg} / \mathrm{ml}$

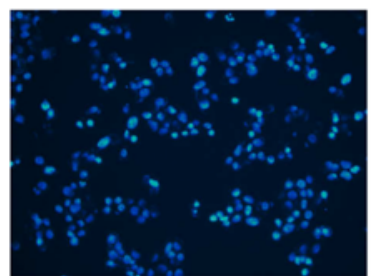

$1.0 \mathrm{mg} / \mathrm{ml}$

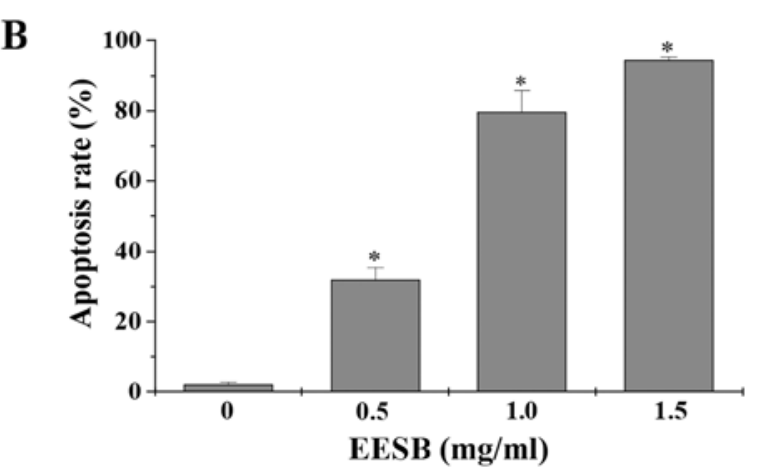

C
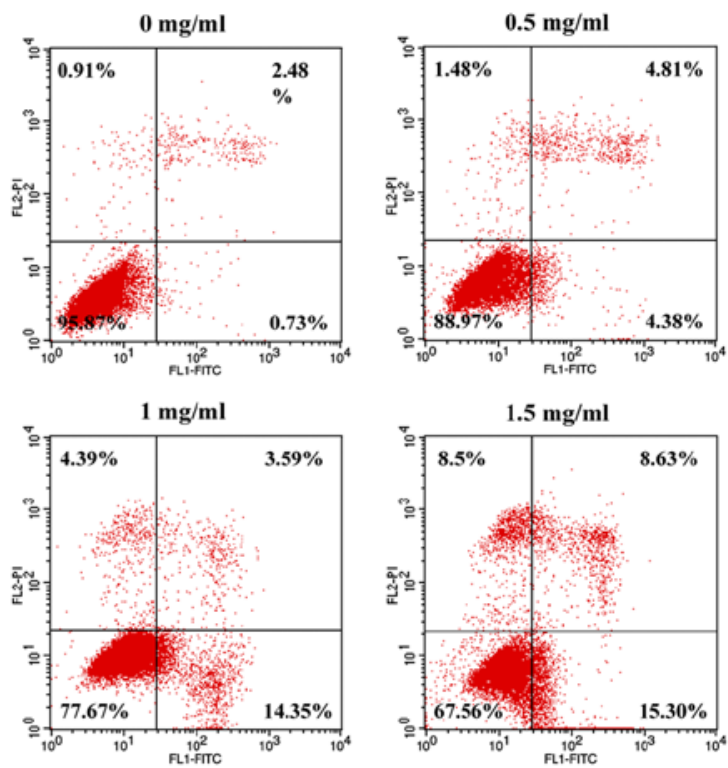

D

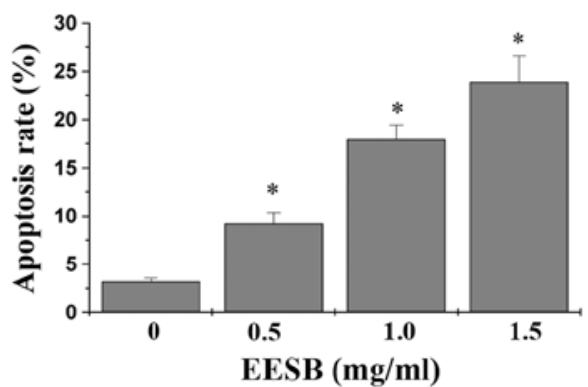

Figure 3. Effect of EESB on apoptosis of HCT-8/5-FU cells. HCT-8/5-FU cells were treated with different concentrations of EESB for 24 h. (A) Cells were stained with DAPI solution. Photographs were taken at a magnification of x200. (B) Stained cells were counted in three randomly selective fields. (C) FACS analysis with Annexin V/PI staining. (D) Quantification of FACS analysis. Data were normalized to the control cells (100\%) and are expressed as mean \pm SD of three independent experiments. ${ }^{\mathrm{P}}<0.05$, versus control cells.
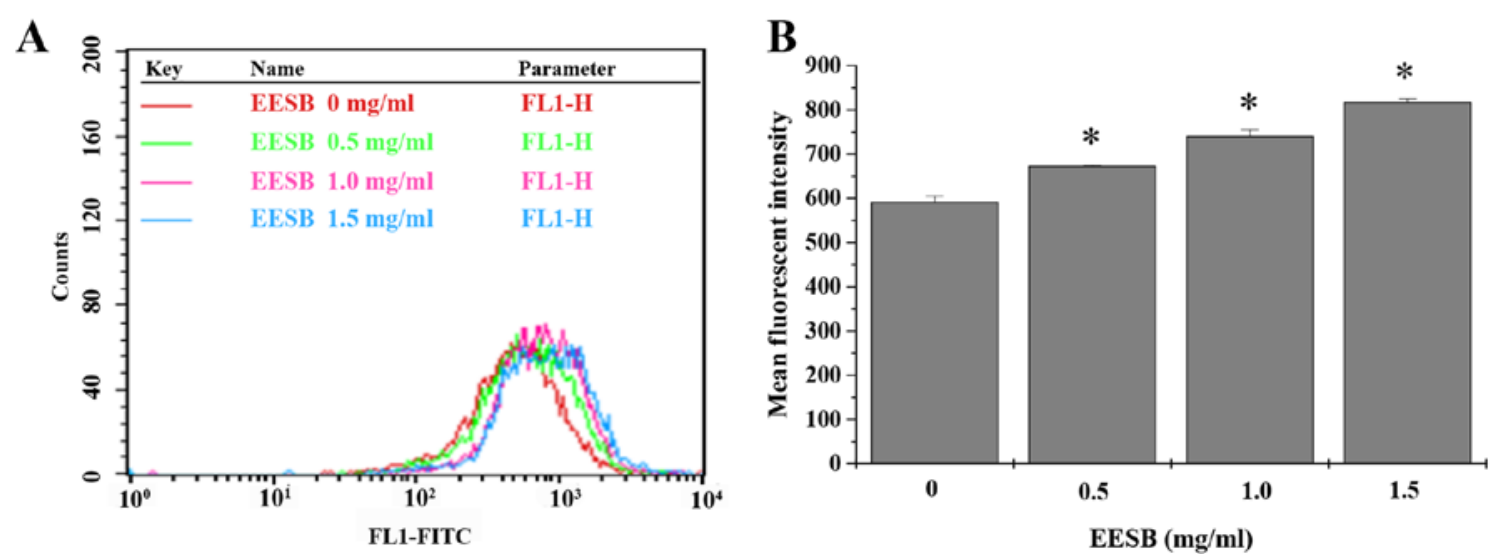

Figure 4. Effect of EESB on drug efflux in HCT-8/5-FU cells. HCT-8/5-FU cells were treated with different concentrations of EESB for 24 h. (A) Cells were incubated with Rh-123 and measured with FACSCalibur flow cytometer. (B) Mean fluorescence intensity of Rh-123 was quantitated. Data were normalized to the control cells $(100 \%)$ and were expressed as mean \pm SD of three independent experiments. ${ }^{*} \mathrm{P}<0.05$, versus control cells.

cell cycle has been shown arrested by many anticancer agents at a particular checkpoint (22-24). Therefore, to develop anticancer and MDR reversal agents, a decisive method is to target the specific cell cycle regulators. MDR cells often show a strong ability of apoptosis resistant due to the imbalance of pro- and anti-apoptosis. In blocking apoptosis, a key role is played by anti-apoptotic $\mathrm{Bcl}-2$ protein, while its overexpression also leads to evasion of apoptosis and the increase of MDR. On the other hand, pro-apoptotic Bax can make malignant cells more sensitive to apoptosis, which leads to overcoming $\operatorname{MDR}(25,26)$, but it is always with a low expression in MDR cells, together with the upregulated Bcl-2, 

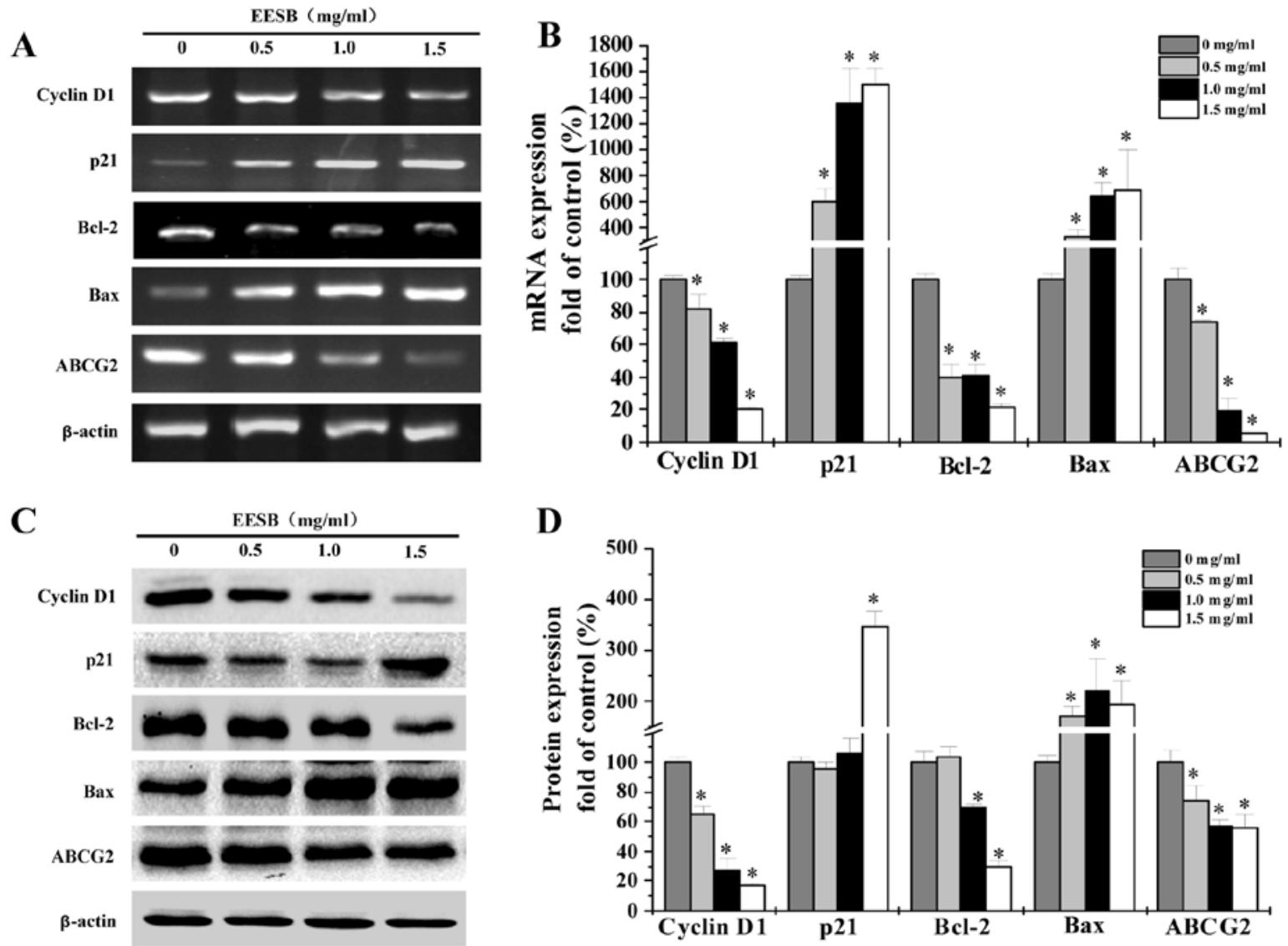

Figure 5. Effect of EESB on expression of cyclin D1, p21, Bcl-2, Bax and ABCG2 in HCT-8/5-FU cells. HCT-8/5-FU cells were treated with different concentrations of EESB for $24 \mathrm{~h}$. The mRNA (A and B) and protein (C and D) expression levels were determined by RT-PCR and western blot analysis, respectively. $\beta$-actin was used as the internal control. Images are representatives of three independent experiments. (B and D) Data were normalized to the control cells $(100 \%)$ and were expressed as mean $\pm \mathrm{SD}$ of three independent experiments. ${ }^{*} \mathrm{P}<0.05$, versus control cells.

$\mathbf{A}$

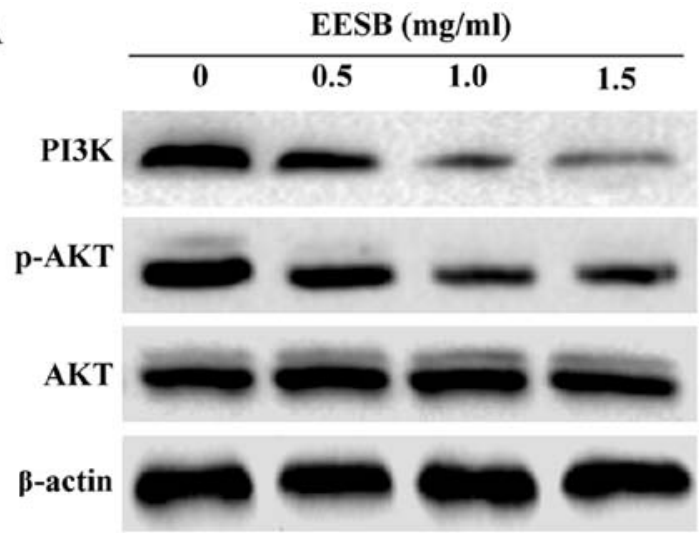

B

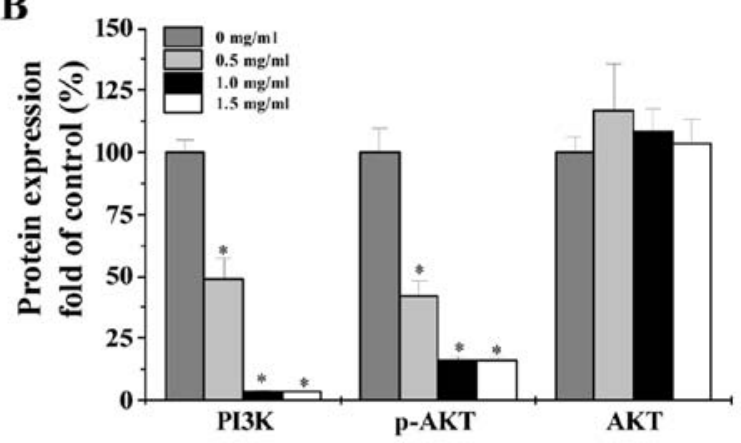

Figure 6. Effect of EESB on activation of PI3K/AKT pathway in HCT-8/5-FU cells. HCT-8/5-FU cells were treated with different concentrations of EESB for $24 \mathrm{~h}$. (A) The expression of PI3K, p-AKT and AKT were determined by western blot analysis. $\beta$-actin was used as the internal control. Images are representatives of three independent experiments. (B) Data were normalized to the control cells (100\%) and were expressed as mean \pm SD of three independent experiments. ${ }^{*} \mathrm{P}<0.05$, versus control cells.

supporting the MDR phenotype. However, the gene therapy directly targeting the cyclin D1, p21, Bcl-2 and Bax remains controversial.

Besides, the high expression of $\mathrm{ABC}$ transporters also draws an attention. $\mathrm{ABC}$ transporters, relating to plasma membrane and depending on consuming energy, work as efflux pumps, effectively putting various substrates across lipid bilayers (27-29). Its role in fighting against xenobiotics and their metabolites has been of great importance $(30,31)$ and this also worked in the ATP-dependent export of chemotherapeutic drugs that makes contribution to the MDR phenotype found in CRC $(32,33)$. When ABC transporters overexpress themselves, many drugs show a reduced level in toxicity and the intercellular accumulation; thus, showing promise in CRC that $\mathrm{ABCG} 2$ can be the target for therapeutic treatment, and effort has been focused on the identification of ABCG2 pharmaco- 
phores and their effective inhibition in the efflux effect (34). Effort to develop reversing agents that target $\mathrm{ABC}$ transporters has been reported, yet in clinical application the limitations of these agents, including the ABCG2 dual inhibitor, Elacridar, have shown poor performance of their solubility and the reduction in oral bioavailability (35-37).

However, it has been reported that without the PI3K/AKT signaling pathway, many cellular functions such as cell cycle, cell proliferation and cell survival cannot regulate normally $(38,39)$. Also, according to several studies, AKT mediate the regulation of $\mathrm{ABCG} 2$ function and localization to the plasma membrane. Such is not the constrain in tumor development but in the tumor's potential response to cancer treatment. Being activated, this pathway has decreasing sensitivity to chemotherapeutics which contribute to treatment failure. Targeting the PI3K/AKT signaling pathway is just like the saying 'to catch bandits, first catch the ringleader' and may become a promising way to deal with the MDR obstacle. A flavonoid derivative, LY294002 (LY), inhibitor of PI3K/AKT pathway, has been reported, but still requires clinical trial (40). Approaches are not many to reduction of side effects and of the risk of inducting drug resistance in CRC, thus proposal to adopt alternative remedies, such as traditional medicines and herbs is being supported by patients and clinicians alike (41).

The effects of EESB, a traditional Chinese herbal medicine, in anticancer use has been revealed as potent, albeit knowledge how EESB works in reducing drug resistance is lacking. This study showed 5-FU effectively decrease the degree of cell viability of HCT- 8 cells, making not significant impact on the drug-resistant HCT-8/5-FU cells (Fig. 1). Different from 5-FU, EESB treatment impressively decreased the cell proliferation and survival of HCT-8/5-FU cells mainly by regulating the related cyclin D1 and p21 (Figs. 2 and 5). Besides, EESB treatment significantly promoted apoptosis of HCT-8/5-FU cells through the rebalance of the Bcl-2 and Bax (Figs. 3 and 5). Moreover, the ABC transporters, ABCG2, is part of the reason why there is MDR phenotype in CRC, and by checking the accumulation assay of the Rh-123, molecularly the efflux activity of ABC transporters in treated cells (42) can be measured. To further clarify how EESB functions as a reversing agent targeting $\mathrm{ABC}$ transporters, flow cytometry was used to evaluate the EESB's role in Rh-123 in accumulation. EESB-treated cells presented obvious increased retention of Rh-123 and lower level of expression of ABCG2, based on the comparison with untreated controls (Figs. 4 and 5), which indicates that EESB may inhibit the efflux function of $\mathrm{ABC}$ transporters and thus increase drug accumulation in treated cells. Since the PI3K/AKT pathway is closely linked to the MDR in CRC, we evaluated the effect of EESB on HCT-8/5-FU cells, the results showed that EESB treatment obviously inhibited the activation of this pathway (Fig. 6).

In conclusion, the results of the present study further assistance in getting insight into EESB that can potently inhibit CRC drug resistance, however, due to the complexity of MDR, further mechanism studies are yet to be elucidated.

\section{Acknowledgements}

This study was supported by the Natural Science Foundation of Fujian Province, China (2015J01337), Project Funding for the Training of Young and Middle-aged Backbone Personnel of Fujian Provincial Health and Family Planning Commission (2016-ZQN-67) and the Developmental Fund of Chen Keji Integrative Medicine (Fujian, China; CKJ2014013 and CKJ2015007).

\section{References}

1. Jemal A, Bray F, Center MM, Ferlay J, Ward E and Forman D: Global cancer statistics. CA Cancer J Clin 61: 69-90, 2011.

2. Markowitz SD and Bertagnolli MM: Molecular origins of cancer: Molecular basis of colorectal cancer. N Engl J Med 361: 2449-2460, 2009.

3. Andersen V, Vogel LK, Kopp TI, Sæbø M, Nonboe AW, Hamfjord J, Kure EH and Vogel U: High ABCC2 and low ABCG2 gene expression are early events in the colorectal adenoma-carcinoma sequence. PLoS One 10: e0119255, 2015.

4. Saika K and Sobue T: Cancer statistics in the world. Gan To Kagaku Ryoho 40: 2475-2480, 2013 (In Japanese).

5. Mastalier B, Tihon C, Ghiţă B, Botezatu C, Deaconescu V, Mandisodza P, Drăghici C and Simion S: Surgical treatment of colon cancer: Colentina surgical clinic experience. J Med Life 5: 348-353, 2012.

6. Van Cutsem E, Nordlinger B and Cervantes A; ESMO Guidelines Working Group: Advanced colorectal cancer: ESMO Clinical Practice Guidelines for treatment. Ann Oncol 21 (Suppl 5): v93-v97, 2010.

7. Xu J, Mo Y, Wang X, Liu J, Zhang X, Wang J, Hu L, Yang C, Chen L and Wang Y: Conditionally replicative adenovirus-based mda-7/IL-24 expression enhances sensitivity of colon cancer cells to 5-fluorouracil and doxorubicin. J Gastroenterol 48: 203-213, 2013.

8. Shain KH and Dalton WS: Cell adhesion is a key determinant in de novo multidrug resistance (MDR): New targets for the prevention of acquired MDR. Mol Cancer Ther 1: 69-78, 2001.

9. Bellacosa A, Kumar CC, Di Cristofano A and Testa JR: Activation of AKT kinases in cancer: Implications for therapeutic targeting. Adv Cancer Res 94: 29-86, 2005.

10. Katso R, Okkenhaug K, Ahmadi K, White S, Timms J and Waterfield MD: Cellular function of phosphoinositide 3-kinases: Implications for development, homeostasis, and cancer. Annu Rev Cell Dev Biol 17: 615-675, 2001.

11. Tazzari PL, Cappellini A, Ricci F, Evangelisti C, Papa V, Grafone T, Martinelli G, Conte R, Cocco L, McCubrey JA, et al: Multidrug resistance-associated protein 1 expression is under the control of the phosphoinositide 3 kinase/Akt signal transduction network in human acute myelogenous leukemia blasts. Leukemia 21: 427-438, 2007.

12. Shekari F, Sadeghpour H, Javidnia K, Saso L, Nazari F, Firuzi O and Miri R: Cytotoxic and multidrug resistance reversal activities of novel 1,4-dihydropyridines against human cancer cells. Eur J Pharmacol 746: 233-244, 2015.

13. Stepanenko AA, Andreieva SV, Korets KV, Mykytenko DO, Baklaushev VP, Huleyuk NL, Kovalova OA, Kotsarenko KV, Chekhonin VP, Vassetzky YS, et al: Temozolomide promotes genomic and phenotypic changes in glioblastoma cells. Cancer Cell Int 16: 36, 2016.

14. Pharmacopoeia of the People's Republic of China. China Medical Science Press, Beijing, pp109-110, 2010.

15. Wei L, Lin J, Wu G, Xu W, Li H, Hong Z and Peng J: Scutellaria barbata D. Don induces G1/S arrest via modulation of p53 and Akt pathways in human colon carcinoma cells. Oncol Rep 29: 1623-1628, 2013

16. Wei L, Lin J, Xu W, Cai Q, Shen A, Hong Z and Peng J: Scutellaria barbata $\mathrm{D}$. Don inhibits tumor angiogenesis via suppression of Hedgehog pathway in a mouse model of colorectal cancer. Int J Mol Sci 13: 9419-9430, 2012.

17. Wei L, Lin J, Xu W, Hong Z, Liu X and Peng J: Inhibition of tumor angiogenesis by Scutellaria barbata D. Don via suppressing proliferation, migration and tube formation of endothelial cells and downregulation of the expression of VEGF-A in cancer cells. J Med Plants Res 5: 3260-3268, 2011.

18. Lin L, Liu Y, Li H, Li PK, Fuchs J, Shibata H, Iwabuchi Y and Lin J: Targeting colon cancer stem cells using a new curcumin analogue, GO-Y030. Br J Cancer 105: 212-220, 2011.

19. Lippman SM: The dilemma and promise of cancer chemoprevention. Nat Clin Pract Oncol 3: 523, 2006. 
20. Longley DB, Allen WL and Johnston PG: Drug resistance, predictive markers and pharmacogenomics in colorectal cancer. Biochim Biophys Acta 1766: 184-196, 2006.

21. Van Cutsem E and Costa F: Progress in the adjuvant treatment of colon cancer: Has it influenced clinical practice? JAMA 294: 2758-2760, 2005.

22. Ji T, Lin C, Krill LS, Eskander R, Guo Y, Zi X and Hoang BH: Flavokawain B, a kava chalcone, inhibits growth of human osteosarcoma cells through G2/M cell cycle arrest and apoptosis. Mol Cancer 12: 55, 2013 .

23. Wu G, Chu J, Huang Z, Ye J, Chen P, Zheng C, Li X, Liu X and Wu M: Xiao Jin Wan, a traditional Chinese herbal formula, inhibits proliferation via arresting cell cycle progression at the G2/M phase and promoting apoptosis via activating the mitochondrial-dependent pathway in U-2OS human osteosarcoma cells. Int J Oncol 42: 1070-1080, 2013.

24. Zheng SE, Xiong S, Lin F, Qiao GL, Feng T, Shen Z, Min DL, Zhang CL and Yao Y: Pirarubicin inhibits multidrug-resistant osteosarcoma cell proliferation through induction of $\mathrm{G} 2 / \mathrm{M}$ phase cell cycle arrest. Acta Pharmacol Sin 33: 832-838, 2012.

25. Wesarg E, Hoffarth S, Wiewrodt R, Kröll M, Biesterfeld S, Huber $\mathrm{C}$ and Schuler M: Targeting BCL-2 family proteins to overcome drug resistance in non-small cell lung cancer. Int J Cancer 121: 2387-2394, 2007.

26. Zhao Y, Zhang CL, Zeng BF, Wu XS, Gao TT and Oda Y: Enhanced chemosensitivity of drug-resistant osteosarcoma cells by lentivirus-mediated Bcl-2 silencing. Biochem Biophys Res Commun 390: 642-647, 2009.

27. Deeley RG, Westlake C and Cole SP: Transmembrane transport of endo- and xenobiotics by mammalian ATP-binding cassette multidrug resistance proteins. Physiol Rev 86: 849-899, 2006.

28. Gottesman MM, Fojo T and Bates SE: Multidrug resistance in cancer: Role of ATP-dependent transporters. Nat Rev Cancer 2: 48-58, 2002.

29. Qiao D, Tang S, Aslam S, Ahmad M, To KK, Wang F, Huang Z, $\mathrm{Cai} \mathrm{J}$ and $\mathrm{Fu}$ L: UMMS-4 enhanced sensitivity of chemotherapeutic agents to $\mathrm{ABCB} 1-$ overexpressing cells via inhibiting function of ABCB1 transporter. Am J Cancer Res 4: 148-160, 2014.

30. Chen Z, Liu F, Ren Q, Zhao Q, Ren H, Lu S, Zhang L and Han Z: Suppression of ABCG2 inhibits cancer cell proliferation. Int J Cancer 126: 841-851, 2010.

31. Zhang H, Wang YJ, Zhang YK, Wang DS, Kathawala RJ, Patel A, Talele TT, Chen ZS and Fu LW: AST1306, a potent EGFR inhibitor, antagonizes ATP-binding cassette subfamily $\mathrm{G}$ member 2-mediated multidrug resistance. Cancer Lett 350: 61-68, 2014.
32. Ee PL, He X, Ross DD and Beck WT: Modulation of breast cancer resistance protein (BCRP/ABCG2) gene expression using RNA interference. Mol Cancer Ther 3: 1577-1583, 2004.

33. Giampieri R, Scartozzi M, Loretelli C, Piva F, Mandolesi A, Lezoche G, Del Prete M, Bittoni A, Faloppi L, Bianconi M, et al: Cancer stem cell gene profile as predictor of relapse in high risk stage II and stage III, radically resected colon cancer patients. PLoS One 8: e72843, 2013.

34. Wang X and Morris ME: Effects of the flavonoid chrysin on nitrofurantoin pharmacokinetics in rats: Potential involvement of ABCG2. Drug Metab Dispos 35: 268-274, 2007.

35. Liu KJ, He JH, Su XD, Sim HM, Xie JD, Chen XG, Wang F, Liang YJ, Singh S, Sodani K, et al: Saracatinib (AZD0530) is a potent modulator of ABCB1-mediated multidrug resistance in vitro and in vivo. Int J Cancer 132: 224-235, 2013.

36. Yang HW, Hua MY, Liu HL, Tsai RY, Pang ST, Hsu PH, Tang HJ, Yen TC and Chuang CK: An epirubicin-conjugated nanocarrier with MRI function to overcome lethal multidrug-resistant bladder cancer. Biomaterials 33: 3919-3930, 2012.

37. Sane R, Mittapalli RK and Elmquist WF: Development and evaluation of a novel microemulsion formulation of elacridar to improve its bioavailability. J Pharm Sci 102: 1343-1354, 2013

38. Arafa SA, Zhu Q, Shah ZI, Wani G, Barakat BM, Racoma I, El-Mahdy MA and Wani AA: Thymoquinone up-regulates PTEN expression and induces apoptosis in doxorubicin-resistant human breast cancer cells. Mutat Res 706: 28-35, 2011.

39. Hegedüs C, Truta-Feles K, Antalffy G, Brózik A, Kasza I, Német K, Orbán TI, Özvegy-Laczka C, Váradi A and Sarkadi B: PI3-kinase and mTOR inhibitors differently modulate the function of the ABCG2 multidrug transporter. Biochem Biophys Res Commun 420: 869-874, 2012.

40. Zhang Y, Wang J, Ren M, Li M, Chen D, Chen J, Shi F, Wang X and Dou J: Gene therapy of ovarian cancer using IL-21-secreting human umbilical cord mesenchymal stem cells in nude mice. J Ovarian Res 7: 8, 2014.

41. Kono T, Hata T, Morita S, Munemoto Y, Matsui T, Kojima H, Takemoto H, Fukunaga M, Nagata N, Shimada M, et al: Goshajinkigan oxaliplatin neurotoxicity evaluation (GONE): A phase 2, multicenter, randomized, double-blind, placebo-controlled trial of goshajinkigan to prevent oxaliplatin-induced neuropathy. Cancer Chemother Pharmacol 72: 1283-1290, 2013.

42. Pallis M and Russell N: P-glycoprotein plays a drug-efflux-independent role in augmenting cell survival in acute myeloblastic leukemia and is associated with modulation of a sphingomyelinceramide apoptotic pathway. Blood 95: 2897-2904, 2000. 